\title{
Energy efficiency obligation schemes: their future in the EU
}

\author{
Tina Fawcett $(\mathbb{D} \cdot$ Jan Rosenow $・$ Paolo Bertoldi
}

Received: 10 November 2017 / Accepted: 29 March 2018 / Published online: 30 April 2018

(C) The Author(s) 2018

\begin{abstract}
EU member states have been encouraged to introduce energy efficiency obligation schemes (EEOS) to help meet energy saving objectives. As a result, there are now 15 EU EEOS in existence, compared with just six prior to the introduction of the 2012 Energy Efficiency Directive. At the same time, the long-standing EEOS in Denmark and the UK have faced challenges because of concerns over increasing costs. This paper considers the role of EEOS in current and future EU and national policy. Firstly, this paper sets out in more detail the place of EEOS in EU energy policy. Then, the future of longer-established EEOS is explored, using Denmark and the UK as case studies. Recent and planned redesigns in these two countries are detailed, with analysis of the factors which led to changes in policy ambition. For new EEOS, key risks to delivery of savings are an overambitious delivery target and time line in the absence of policy learning opportunities. The policy risk for nine
\end{abstract}

T. Fawcett $(\bowtie)$

Environmental Change Institute, University of Oxford, South Park Road, Oxford OX1 3QY, UK

e-mail: tina.fawcett@eci.ox.ac.uk

J. Rosenow

Regulatory Assistance Project, Rue de la Science 23,

1040 Brussels, Belgium

J. Rosenow

Centre on Innovation and Energy Demand, University of Sussex, Jubilee Building, Falmer, Brighton BN1 9QE, UK

\section{P. Bertoldi}

European Commission, JRC, Directorate Energy, Transport and Climate, Via E. Fermi 1, 21027 Ispra, (VA), Italy
EEOS is assessed, with savings being most at risk in Croatia, Latvia and Spain. The paper concludes with an analysis of EEOS within the future policy mix. The discussion considers the place of EEOS in evolving EU policy, future savings from EEOS, their relationship with energy companies and the possible influence of different framings of energy efficiency. The continuing need for EEOS is explored, with concluding ideas about how to secure a strong and effective future for this policy tool.

Keywords Energy efficiency obligation schemes . Efficiency $\cdot$ Policy $\cdot$ EU $\cdot$ UK $\cdot$ Denmark

\section{Introduction}

Globally energy efficiency is increasingly understood as a key component of low-carbon energy policy (IEA 2016). The European Union (EU) is committed to energy efficiency as a key component of its energy strategy: this is exemplified by its headline aim of delivering $20 \%$ improvement in energy efficiency by 2020 . Targets for 2030 are currently being negotiated, with proposed overall targets of 30 and $35 \%$ energy saving compared with business as usual, from the European Commission and the European Parliament respectively. In many countries now, the question is not whether energy efficiency should be delivered, but how best to do so. Which policies and policy mixes are most effective and cost-effective, and how should they be implemented? These questions are even more relevant with the 
ratification of the UN Paris Agreement (UNFCCC 2015) which sets an aspirational limit to global temperature rise at $1.5{ }^{\circ} \mathrm{C}$, rather than the $2{ }^{\circ} \mathrm{C}$ which formed the basis for much of earlier policy making. This paper considers the current and future role of one particularly important policy-energy efficiency obligation schemes - for the EU and its member states.

Energy efficiency obligation schemes (EEOS) emerged out of a debate in the USA in the 1970s and 1980 s around least-cost planning and later in the 1990s around integrated resource planning - an approach that requires systematic consideration of energy efficiency as a means for achieving outcomes more cheaply. An EEOS requires obligated parties, generally energy utilities, to meet energy saving targets by delivering or procuring energy savings at the customer end of the energy system. Within this general definition, individual EEOS look very different from each other, with obligations being variously placed on energy retailers, energy distributors, or both; across different geographical scales; on a variety of energy types; with different levels of ambition and metrics; and across all sectors of the economy, or just for particular customer groups. This policy has been implemented in very different market structures and policy mixes, and no two countries or regions have identical EEOS. In the USA, these obligations are called energy efficiency resource standards (EERS) and have been adopted in 26 states, even in the absence of a federal mandate (Nadel et al. 2017). There are estimated to be around 46 EEOS across the globe (IEA 2017).

EEOS were promoted at EU level primarily because there is good quality evidence, from the EU and beyond, that well-designed EEOS can deliver significant, costeffective energy savings over many years (Bertoldi et al. 2010; ENSPOL 2015a, b; RAP 2012). The evidence base for the social and economic value of EEOS is strong and growing (e.g. Labanca and Bertoldi 2016; Rosenow and Bayer 2016). However, the literature also stresses that the performance of schemes is determined by the details of policy design, implementation, governance and market structure and conditions (Eyre et al. 2009; Mundaca and Neij 2009). The success of an energy efficiency obligation scheme cannot be taken for granted.

The EU has a range of policies to require member states to improve the efficiency with which energy is used (Pereira and Pereira da Silva 2017). The Energy Efficiency Directive (EED - 2012/27/EU) is the over- arching directive, which sets binding national energy efficiency targets up to 2020, and includes additional policy requirements and tools which help member states to achieve their targets. Adoption of EEOS is specifically mandated within Article 7 of the EED, in addition to a full range of other policy options - known as alternative measures. ${ }^{1}$

Despite this encouragement, not all EU countries have chosen to introduce EEOS. In 2015, 16 member states had implemented, planned, or were actively considering the implementation of EEOS (ENSPOL 2015c). Since then, Estonia, Lithuania and Hungary have dropped their plans for EEOS, and others have introduced schemes. The number of member states with an active EEOS is now 15 (Table 1) with 13 member states having decided (to date) they can meet their energy savings targets without this policy instrument.

EEOS had been in place in a number of member states prior to the introduction of the Energy Efficiency Directive. The longest-established have been those in the UK and Denmark, both in operation in some form for around 20 years. These EEOS have delivered higher savings than in other EU countries (ENSPOL 2015a) and so could be seen as front runners. However, in both countries, the increasing ambition of savings targets, and the cost of the schemes to bill payers has raised political and public concern. This has influenced recent reductions in their savings targets. So while EEOS have a good track record of success and are being adopted by the majority of EU member states, this is a good point in time to consider their future role.

This paper questions whether established EEOS can continue to deliver significant savings, whether new schemes will meet their targets and if EEOS have an important future role. Firstly, the paper sets out in more detail the place of EEOS in EU energy policy. This is followed by a description of the methodology used to answer the research questions. Then, the future of longer-established EEOS is explored, with case studies from the UK and Denmark. The new EEOS, their ambition levels and learning periods are described, and the risks of under-delivery of savings are assessed. The discussion focuses on the future prospects for EEOS. It considers the place of EEOS in EU policy, future

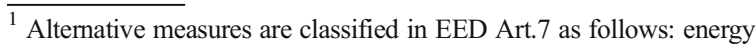
efficiency national fund, energy or $\mathrm{CO}_{2}$ taxes, financing scheme or fiscal incentive, regulation or voluntary agreements, standards and norms, energy labelling schemes, training and education, and other policy measures.
} 
Table 1 EEOS in EU member states, current status

\begin{tabular}{ll}
\hline EEOS status & Member states \\
\hline Active & Austria, Bulgaria, Croatia, Denmark, France, \\
& Greece, Ireland, Italy, Latvia, Luxembourg, \\
& Malta, Slovenia, Spain, Poland, the UK \\
None planned & Belgium, Cyprus, Czech Republic, Estonia*, \\
& Finland, Germany, Hungary*, Lithuania*, \\
& the Netherlands, Portugal, Romania, \\
& Slovakia, Sweden,
\end{tabular}

*EEOS were planned, but these plans have been withdrawn

savings from EEOS, their relationship with energy companies and the possible influence of different framings of energy efficiency. The conditions under which EEOS would no longer be a valuable policy option are explored. The paper concludes with thoughts about how to secure a strong and effective future for EEOS.

\section{Policy background}

\section{EEOS within EU efficiency policy}

Energy efficiency is one of five closely related and mutually reinforcing dimensions in the EU's energy union strategy, which was created to achieve a secure, affordable and climate-friendly European energy system. EU efficiency policy has been implemented through three key directives-Ecodesign (2009/125/ EC), Energy Performance of Buildings (EPBD 2010/31/EU) and the Energy Efficiency Directive (EED - 2012/27/EU). As their names suggest, the Ecodesign Directive covers the energy efficiency of products, EPBD covers aspects of energy use in buildings and EED is an over-arching directive. Under EED, EU countries are required to use energy more efficiently at all stages of the energy chain from its production to its final consumption.

Within the EED, Article 3 requires that member states set an indicative national energy efficiency target. This target includes savings delivered by all national and EU-level actions, including new action under other provisions in the Energy Efficiency Directive. EED includes several provisions and new routes to deliver savings - including energy audits and energy management systems, EEOS and action in public sector buildings. EED Article 7 sets national energy savings targets for 2014-2020 to be delivered by EEOS and/or 'alternative measures'. This target must be based on a nominal savings rate of $1.5 \%$ per year compared to the average energy consumption in the period 2010-2012. However, the total energy savings target may be lower; this is because of member states' use of exemptions and exclusions, as allowed in the legislation (Fawcett and Rosenow 2016). As a result, the notified saving targets are only about half of this headline figure, i.e. the annual saving rate is about $0.75 \%$ (Forster et al. 2016; RicardoAEA 2015).

EEOS are a key policy tool: analysis of member state reports shows they are expected to deliver $34 \%$ of Article 7 savings - the biggest contribution of any policy instrument. Other savings will come from financing schemes or grants $(19 \%)$, and taxes $(14 \%)$, regulation/ voluntary agreements $(11 \%)$, standards and norms $(9 \%)$ with smaller contributions from training, national energy efficiency funds, energy labels and any other policy measures (Forster et al. 2016). Note that these figures should be viewed with some caution - they are ex ante estimations and not measured savings, and there are considerable uncertainties around their reliability (Rosenow et al. 2016b).

National Article 7 targets can be met by delivering energy savings from all sectors of the economy and energy end-uses. However, experience to date is that savings have been unevenly distributed between sectors and end-uses: most savings are expected from multisector 'cross cutting' policies (44\%), followed by buildings (42\%), industry (8\%) and transport (6\%) (Forster et al. 2016). This pattern is influenced by requirements within Article 7, particularly the requirement for 'additionality' - which means savings have to be additional to those which are expected from existing EU efficiency policies. In practice, this means that most savings are likely to come from efficiency improvements to buildings (beyond those mandated in the Energy Performance of Buildings Directive) or industrial processes and their management. Efficiency improvements to products, e.g. lightbulbs, boilers or motors, are largely non-additional as these are delivered via the Ecodesign Directive. Similarly, additional savings from transport are likely to be limited, as the efficiency of new vehicles is also mandated by existing legislation (Regulation (EC) Nos. 443/2009, 333/2014). Article 7 differs from earlier legislation on energy efficiency in its complexity and flexibility (Rosenow et al. 2016b). It is trying to influence the more difficult areas for policy to reach, without a clearly defined route to doing so. 
EU policy support for EEOS beyond 2020

On November 30, 2016, the European Commission published a comprehensive set of energy proposals called 'Clean energy for all Europeans', also known as the Winter Package (European Commission 2016a). The aim of the package of measures is to keep the European Union competitive as the clean energy transition is changing the global energy markets'. Included in the proposals is an extension of the energy savings requirement of Article 7, EED to 2030. The proposal also suggests that Article 7 be amended to make it clear that member states can achieve the required energy savings through an energy efficiency obligation scheme, alternative measures or a combination of both approaches (European Commission 2016b). In fact, this is not substantively different from the original Article 7. In addition, an overall target of $30 \%$ energy saving for 2030 is proposed. This target has been debated extensively in advance of the Commission's proposals, with the European Parliament calling initially for a target of 40\% (European Parliament 2016). In 2018, the Parliament endorsed committee proposals for binding EUlevel targets of a 35\% improvement in energy efficiency (European Parliament 2018). The final decision on targets and other legislative details is expected during 2018.

\section{Methodology}

This paper addresses three research questions: whether established EEOS can continue to deliver significant savings, whether new schemes will meet their targets and if EEOS have an important future role. The first question is investigated by providing structured, analytical case studies of the two longest-established EEOsthose in the UK and Denmark. There are two key reasons for choosing these examples and excluding the long-running schemes from France and Italy. First, a closer focus on just two cases allows more detailed description and analysis. Secondly, the savings ambition of the UK and Danish schemes has recently been reduced, which has not happened in France and Italy. Thus, they are of greater relevance in answering the research question. To answer the second question, firstly, key characteristics of successful EEOS are distilled from the literature. Then, the characteristics of the newer schemes are compared with these characteristics, and conclusions drawn on their likely success. Findings from both sets of analysis are brought together, along with reflection on broader trends in energy and energy policy, to inform a discussion on the future role of EEOS.

\section{Future of long-established EEOS}

EEOS have been in place in a number of member states prior to the introduction of the Energy Efficiency Directive, namely Bulgaria, Denmark, France, Italy, Poland and the UK. Briefly, in Denmark, France, Italy and the UK, up until 2013, each national scheme has been increasing the energy savings targets to be achieved, while also evaluating progress and amending scheme rules to meet changing objectives and circumstances. These schemes are generally considered to have been successful in delivering significant, cost-effective savings. The picture in Poland is more complex as the first phase of the scheme was not successful, and the EEOS has been comprehensively redesigned (ENSPOL 2015a). In Bulgaria, an existing EEOS scheme is reported as having been adapted to fit with the requirements of EED (Republic of Bulgaria 2016). The Bulgarian EEOS is less well documented (in English) than the other schemes. In addition to these national schemes, the Belgian region of Flanders also had a very successful EEOS (ENSPOL 2015a).

The longest-established EEOS are those in the UK and Denmark, both in operation for around 20 years, and these are described in more detail below. Despite their successes, in both countries, the increasing ambition of savings targets and the cost of the schemes to bill payers have raised political and public concern. This has influenced reductions in their savings targets. Understanding how these EEOS have developed in recent years, what concerns were raised about their impact and how the public debate evolved should help other countries retain support for ambitious savings targets.

\section{UK case study ${ }^{2}$}

The EEOS began in 1994, when the UK was the first country in Europe to impose energy efficiency obligations on energy suppliers. Suppliers were allowed to

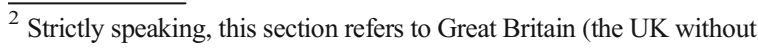
Northern Ireland) - but we use UK, as it is more familiar.
} 
raise money to meet energy savings targets from a charge on residential and small and medium enterprise (SME) customer bills. SMEs were no longer included in the scheme from 2002 and subsequently, it has covered the residential sector only, a feature which is unique in the EU. The scheme has been redesigned approximately every 3 years, and four different names have been employed since 1994. The current scheme, 20132017, is called ECO - the Energy Company Obligation. The UK objectives, measures, savings, costs and mechanisms have varied over time. These are described more fully elsewhere (ENSPOL 2015a; Rosenow 2012).

Redesigns prior to 2013 were primarily aimed at increasing the savings delivered. The success of early phases of the scheme led to confidence that suppliers could reach higher targets. The obligations started at a relatively low level but eventually became a major climate change mitigation policy for the residential sector. In 2008-2012, the scheme was saving around $1 \%$ of UK residential energy use annually. Until the sudden changes adopted in 2013, EEOs had developed incrementally and grown steadily in scale (Fig. 1), resulting in general support as a policy mechanism across changes in political administration and market structure. Targets in Fig. 1 are 'estimated' because UK targets are set in terms of lifetime carbon savings, and these have to be translated into annual energy savings.

The policy redesign of ECO (2013-2017) was to ensure it fit well with a significant new policy, the 'Green Deal' loan scheme. Green Deal was expected to establish a new market for energy efficiency measures for 'able to pay' customers, installing measures previously subsidised through the earlier EEOS phases. ECO was designed to

1. support insulation measures in any household that were too expensive to meet the Green Deal funding rules, such as solid wall insulation, and
2. to provide support for a wider range of measures to vulnerable customers, largely people receiving social benefits who would not be expected to take on Green Deal loans (DECC 2011).

It was also designed, in part, to take account of the ending in 2011 of the government-funded programme designed to reduce fuel poverty. Thus, the EEOS had changed from a scheme which supported large-scale installation of cheaper measures (particularly loft and cavity wall insulation) to a scheme primarily targeting expensive insulation measures - not because all the available cheaper measures had been installed, but because the government judged they should no longer be generally subsidised. Unfortunately, Green Deal was a very unsuccessful policy, with minimal take of up loans, and it was effectively withdrawn in July 2015 (Rosenow and Eyre 2016).

In mid-2014, ECO was redesigned 'to reduce pressures on consumer bills and ensure ECO provides value for money for energy consumers; whilst continuing to help tackle fuel poverty, support the development of a sustainable energy efficiency supply chain and improve the energy efficiency of our housing stock' (DECC 2014a). As well as reducing the savings target of the main strand of ECO by $33 \%$, some cheaper measures were reintroduced to the scheme from 2015.

A number of factors influenced this decision:

- Energy companies argued that targets could not be delivered at the costs suggested by government, and cheaper measures needed to be included.

- The markets for low-cost insulation measures (loft and cavity wall insulation) originally excluded from ECO had been severely damaged due to the very low uptake under Green Deal. The job losses entailed, and concern about this business sector put pressure on the government to make changes.
Fig. 1 Estimated annual energy savings of the EEOS in the UK, 1994-2017. Source: Rosenow ((2012, 2013), 1994-2012), author estimate 2013-2017

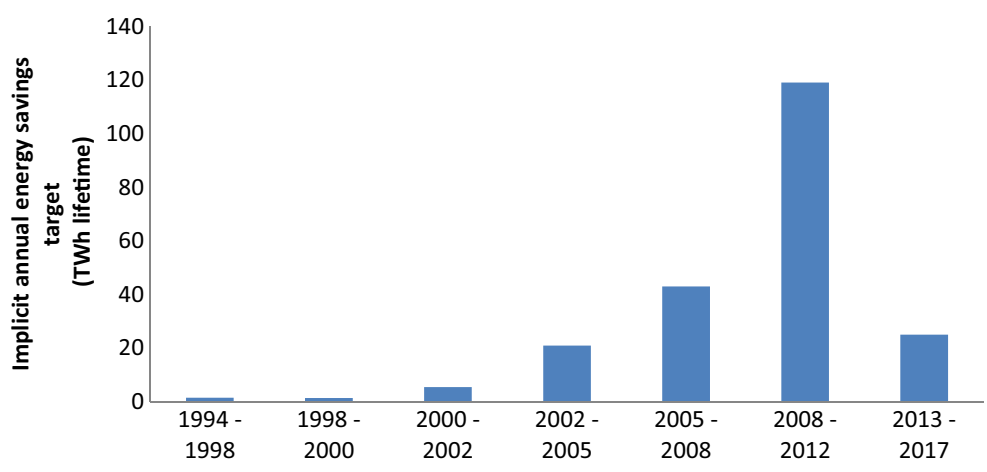


- Very high levels of public concern about energy prices led to pressure on government to reduce 'levies', which is how the cost of ECO was presented by its opponents (Rosenow and Eyre 2016).

The savings target was reduced, despite the overwhelming contrary response to the government consultation (DECC 2014a) and government evidence that this would result in net higher energy bills overall (DECC 2013).

The government plans to keep ECO as part of its policy mix with plans for a supplier obligation to run for 5 years from April 2017 at an estimated level of $£ 640$ million $(€ 732 \mathrm{~m})$ per year. It has designed an interim scheme for an 18-month period from April 2017 to September 2018, which will act as a transition towards a longer term scheme from 2018 to 2022 (BEIS 2017a).

Figure 2 shows the government's intention in outline in terms of the content of the policy. The transitional extension for 2017-2018 will be smaller in terms of expected energy company spend (26\% reduction), with more of a focus on the fuel poor-both moves will reduce energy savings delivered. In October 2017, the UK government published its 'Clean Growth Plan' (BEIS 2017b). In this, it has committed to extend support for home energy efficiency out to 2028 at least at the current level of ECO funding. It will review the best form of support beyond 2022 'recognising the need to both save carbon and meet the Government's commitment to upgrade all fuel poor homes to EPC Band C by 2030' (BEIS 2017b, p. 77).

The recent and planned changes to the UK scheme were not inevitable. They were driven by a number of factors - with political concerns, within a programme of economic austerity, being the key. Governments, of course, are entitled to make political decisions. The current plans mean that the UK will use its future EEOS to tackle fuel poverty rather than introduce fuel poverty policies funded through general taxation, an alternative way of funding energy efficiency but incompatible with austerity politics. This raises questions as to whether this will retain public support, and if is it a sufficient or sensible way to address fuel poverty. Given that the future EEOS is not designed to deliver significant energy savings (DECC 2016), there will be a gap in the UK policy mix designed to meet Article 7 targets. Whatever the future relationship of the UK with the EU, it still needs strong energy efficiency policy and effective delivery to meet its national carbon reduction targets (CCC 2015).
Danish case study

Denmark has had an EEOS for about 20 years. There have been several phases of the EEOS in Denmark; the overall policy objective of delivering cost-effective savings has not changed significantly, but the means by which energy savings have been delivered. The different phases have built on experience and adapted to external factors such as the development of the energy system, technological development, and the consequences of other policies. Over time, the Danish scheme has included increasing numbers of energy distribution companies (also known as DSOs-which are regulated monopolies), supplying different fuels, including smaller companies. It has also increased the savings targets, moved towards supporting technological measures rather than education and advice, and has implemented more formal procedures to calculate and document savings and ensure additionality. The scheme is based on a voluntary agreement between the energy trade associations and the government (although obligations can be imposed if actors refuse to take part voluntarily). This scheme is widely considered to be successful.

The Danish EEOS began with electricity companies in the 1990s. Initially, the focus was on awareness information, education and campaigns. The scheme covered private households, industry, trade and services sector and the public sector. In 2000, the gas distribution companies joined the scheme. From 2006, the scheme was changed radically, with savings targets being introduced which were two to three times higher than previously. The focus moved to implementation of energy savings. At this stage, the oil companies joined the scheme, and district heating companies either joined voluntarily or were required to realise energy savings under the same conditions as the companies that joined the agreement. In 2009, more precise requirements for documentation of savings were introduced to ensure alignment between the DSOs and to increase additionality. As the size of the obligation grew, there was also an increased focus on costs and their documentation. In 2010, the EEOS target was doubled, and it has continued to increase over time (Fig. 3). The 2015-2020 target is equivalent to saving $3 \%$ of final energy in Denmark, excluding transport. A more detailed account of the development of the EEOS is available elsewhere (ENSPOL 2015a).

The current Danish EEO, known as 'The Energy Savings Agreement', runs from 2012 to 2020 and is 
Fig. 2 Change in design of UK EEOS, 2013-2022

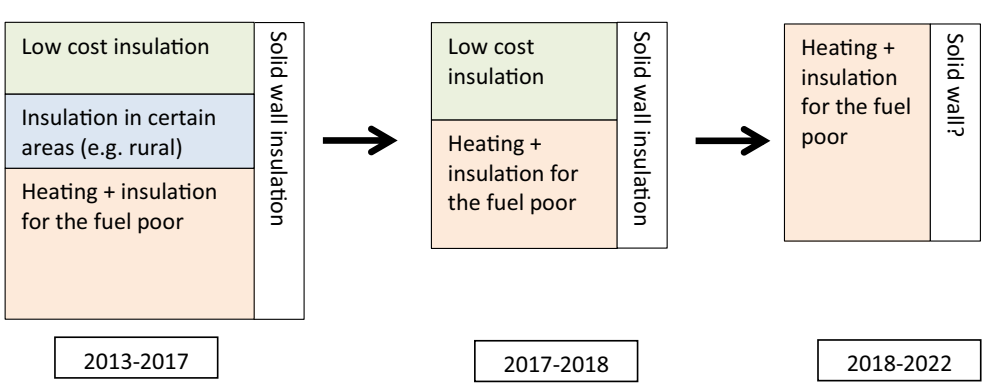

(not to scale). Adapted from DECC (2016) renegotiated every 3 years. Evaluations of the scheme feed into the renegotiation process and can be influential (Bundgaard et al. 2013). For the first time in the history of the scheme, savings targets in 2013 and 2014 were not met. In 2015, obligated parties looked into the possibility of realising more savings in the transport sector and energy production and from SMEs (ENSPOL 2015a). The savings target in 2015 was met (Bach 2016).

In the summer of 2016, politicians proposed that the obligation should be moved from distributors to retailers. This was in part due to their belief that this would deliver more competition and ultimately result in cheaper energy efficiency/energy savings, benefiting customers (Pers. Comm., Nikolaj Nørregård Rasmussen, June 13, 2016). Their views were influenced by two Danish studies about reforming the EEOS, one official and the other unofficial. This change would represent a major disruption to the Danish scheme. Discussions about future changes are continuing, but the DSOs are currently expected to remain the obligated parties until at least 2020. However, the latest agreement between the government and obligated parties (signed late December 2016) has reduced the savings target to $10.1 \mathrm{PJ}$ per annum for 2016-2017 (Pers. Comm., Mikael Togeby, January 16, 2017).

\section{Introduction of new EEOS}

In 2016, new EEOS were present in Austria, Bulgaria, Croatia, Ireland, Latvia, Luxembourg, Malta, Slovenia and Spain (for more details, see Bertoldi et al. (2015); Fawcett and Rosenow (2016). Since then, Greece has also introduced a scheme, starting in 2017 (ATEE 2017). The Polish scheme has been completely redesigned after failure to deliver significant savings in the first phase and can be treated as a new EEOS. There is a lot of high- quality advice on how to design, implement, monitor and evaluate an EEOS (Lees and Bayer 2016; RAP 2012) in addition to EU-level initiatives to encourage mutual learning between member states (e.g. the ENSPOL project, the bigEE project, Concerted Action programme).

A key question is whether the new EEOS are likely to emulate the success of schemes in Denmark, France, Italy and the UK in delivering significant energy savings over a sustained period. Success is not determined by who the obligated party is, the way the targets are set, the sectors across which it operates and the degree of tradability of savings - which have varied between these countries. Factors that the successful schemes have in common are the following: (1) beginning with modest levels of savings; (2) increasing in ambition level over time; (3) learning from early phases and redesigning the EEOS to be more efficient and effective; (4) consistently evaluating the performance of the EEOS and having an independent authority to check them and be ready to implement sanctions if savings are not delivered; (5) having effective sanctions in case of non-compliance and (6) transparent methods of calculating savings. The established schemes have proven that they can deliver high levels of savings, so it is clear that EEOS of the right design and implementation can deliver a considerable share of a country's Article 7 savings.

Current Article 7 targets have to be met between 2014 and the end of 2020, giving a relatively short time for newly introduced EEOS to deliver significant savings (although the Winter Package is now expected to extend the time frame to 2030). Successful schemes typically have limited savings targets on introduction. In France, the first 3 years of the EEOS (2006-2009) were treated as a trial period with low savings targets, so that obligated parties could acclimatise to the system and build relationships with the various stakeholders needed to deliver measures. The scheme was redesigned after experience in the first phase. There was a similar 
Fig. 3 Danish EEOS - annual energy savings targets, 20052020, expressed as first year savings. Source: Bach (2016), plus personal communication as in text below

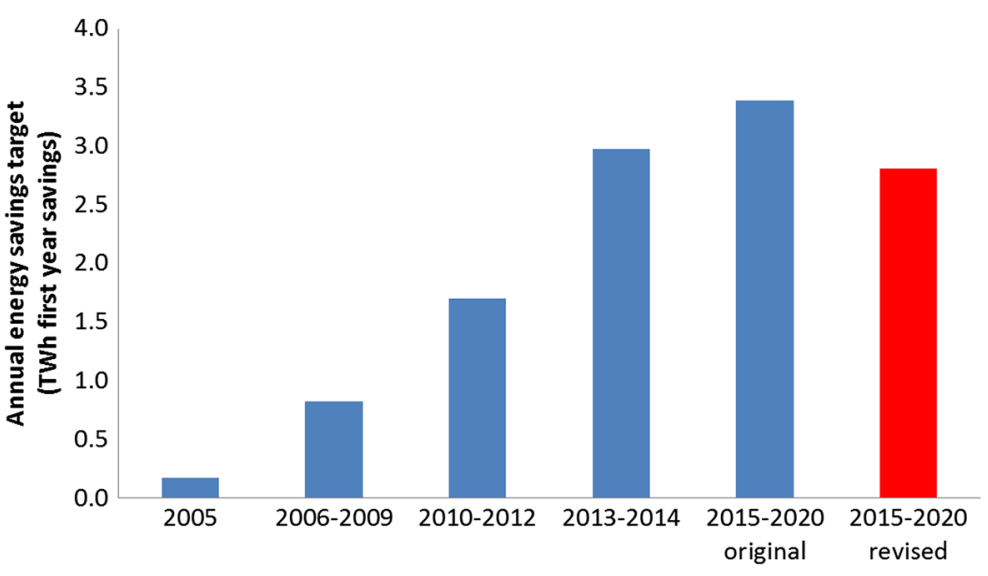

pattern of gradual introduction, learning and redesign in Italy and Denmark. In the UK, significant savings targets were only set after the first 8 years of the scheme. ${ }^{3}$ However, the time it typically takes before EEOS can deliver significant savings can be cut short in the new EEOS schemes.

Two ways in which the initial learning period could be shortened are as follows:

(1) build on existing experience of a voluntary scheme for obligated parties;

(2) adopt (and adapt) a successful EEOS design from another country.

Each of the new EEOS is assessed against those criteria to establish whether or not the schemes are likely to be at risk of delivering lower savings than anticipat$\mathrm{ed}^{4}$ (Table 2). Our assessment is subjective and based on limited evidence in literature and assessment reports. However, this evidence shows that all successful schemes display either a learning period or are modelled on successful EEOS. In the absence of either of the two factors, it is much more likely that new EEOS will under-deliver. A good example is the Polish EEOS which was very ambitious in terms of the target, complex in design but unsuccessful in delivering significant savings in its first iteration.

\footnotetext{
${ }^{3}$ This was a result of limited regulatory powers of the regulator and not driven by the need for learning. Without the limitations that were overcome in 2002, the targets most likely would have been increased earlier (Rosenow 2012).

${ }^{4}$ Risk of savings shortfall is only estimated against these criteria. We have not considered whether member states have sufficient low costefficiency opportunities which can be delivered by their EEOS.
}

The analysis shows that of these approaches, Austria, Ireland and Slovenia have taken the first approach, and Luxembourg has taken the second. Having taken neither of these approaches, and having fairly ambitious targets, Croatia, Latvia and Spain are at high risk of savings shortfalls - they may not deliver savings at the anticipated rate. Given the problems with Phase 1 of its EEOS and its high ambition level, saving from the Polish scheme must also be at some risk.

\section{Discussion}

This discussion focuses on the future prospects for EEOS, picking up on the evidence presented earlier and wider trends in energy and energy policy. It considers first the place of EEOS in EU policy, future savings from EEOS, their relationship with energy companies and the possible influence of different framings of energy efficiency. Then, thoughts about what it would take to not need EEOS as an option in the policy mix are presented, with concluding ideas about how to secure a strong and effective future for EEOS.

\section{EEOS in EU policy}

The EU's Winter Package has reaffirmed that EEOS have a future in meeting European and national energy saving goals, with the proviso that meaningful energy savings targets are set. Not all countries see them as a necessary policy however, with a number of member states choosing not to use an EEOS. There may simply not be the need for an additional policy within a national policy mix, or the energy market structure may not be conducive to EEOS. Most of the longer-established 
Table 2 Risk of policy failure based on presence of voluntary phase and/or adoption of successful designs

\begin{tabular}{lclll}
\hline & $\begin{array}{l}\text { Ambition level (share } \\
\text { of EEOS of total } \\
\text { Article 7 savings) }(\%)\end{array}$ & $\begin{array}{l}\text { Voluntary } \\
\text { phase }\end{array}$ & $\begin{array}{l}\text { Adoption of } \\
\text { successful } \\
\text { design }\end{array}$ & $\begin{array}{l}\text { Risk of savings } \\
\text { shortfall }\end{array}$ \\
\hline Austria & 42 & $\checkmark$ & & Low \\
Croatia & 41 & $\checkmark$ & High \\
Ireland & 48 & & Low \\
Latvia & 65 & & High \\
Luxembourg & 100 & & & Low \\
Malta & 17 & & & Moderate \\
Poland & 100 & $\checkmark$ & Moderate \\
Slovenia & 33 & & Low \\
Spain & 44 & & High \\
\hline
\end{tabular}

Source: authors' illustration; share of EEOS of total Article 7 savings taken from Fawcett and Rosenow (2016) residential sector in France and the UK, and predominantly from the industrial sector in Denmark or Italy ${ }^{5}$ although residential savings are becoming more important in both of these countries as well now (ENSPOL 2015a). In the residential sector, EEOS have been used primarily to deliver relatively low-cost energy-efficiency measures. This clearly maximises benefit-cost ratios, but does not support more comprehensive, whole-house retrofits. This may prove important in the context of the need to deliver substantial change in the built environment, as it is difficult to see how EEOS focused primarily on cost-effectiveness will support deep and complex refurbishment, one of the key challenges within energy efficiency policy.

Given the limited experience with using EEOS for delivering deeper energy efficiency improvements, it is difficult to predict whether or not this type of policy instrument can deliver more costly and complex energy saving measures. In theory, if EEOS are to deliver deeper and more comprehensive energy efficiency improvements in residential (and other) buildings, in principle, this can be achieved by (a) establishing incentives for deeper energy efficiency improvements and (b) limiting the extent to which the most cost-effective measures can be utilised. Both of these moves have been incorporated in the UK scheme, with quotas for (relatively expensive) solid wall insulation, and limits on installation of cheaper measures - as described briefly earlier.

Including fewer, more expensive measures in EEOS has social equity implications. EEOS are funded

\footnotetext{
${ }^{5}$ Previously, the residential sector dominated savings from the Italian EEOS but after a change in the calculation methodology in 2012 valuing the benefits of longer-lived measures, there has been a shift to industrial measures.
} 
through energy bills, which means that all customers pay for the programme. If the EEOS saving target is delivered via fewer projects, a smaller number of people and organisations benefit from the scheme. In other words, the benefits are concentrated and the costs are dispersed. This can become controversial. The same is true for other energy efficiency finance policies that rely largely on public subsidies and is not uniquely problematic for EEOS.

However, there are ways to dampen the effect of concentrated energy saving benefits versus dispersed energy bill costs: in France, many energy efficiency measures are part-funded by EEOS and tax rebates which results in lower EEOS bill surcharges (Rohde et al. 2015). In principle, such an approach could be used to employ EEOS for the purpose of delivering technologies with higher costs and deeper energy efficiency improvements. The EEOS would be the primary delivery mechanism and the firm targets ensure that energy savings are being achieved. At the same time, funding for less cost-effective measures would be provided by a mechanism funded through general taxation in order to part-fund those measures together with the EEOS. Using multiple policy instruments in this way increases the risk of double-counting and lack of additionality. This would have to be recognised and guarded against in policy design and implementation.

\section{EEOS and energy companies}

The unique feature of EEOS is that they are an obligation on energy companies, whether retailers, distributors or both. Because of this, the way in which energy company relationships with their customers are changing, driven by changes in the energy landscape, is relevant to the future of this policy. For example, more consumers are generating their own energy and selling as well as buying from their energy retailer, and are becoming 'prosumers' (Parag and Sovacool 2016). The roll-out of smart meters (European Commission 2014) and feedback options means that customers can be better informed than ever about their own energy use. The rising percentage of renewables in the electricity generation mix has increased interest in customers' capacity for 'demand response' (Grunewald 2016). These and other developments may lead to more engaged, active customers with greater interest in the benefits of energy efficiency. If energy customers are more active, then it should be easier for energy companies to engage them in EEOS programmes and to deliver their savings targets. This would also apply more generally to energy policies promoting energy efficiency, demand response or uptake of renewable energy. However, these more engaged customers may seek out energy savings opportunities themselves, and not be so reliant on incentives and information delivered by EEOS and other policy instruments, which will then target the less-engaged.

One of the anticipated benefits of EEOS is that they would change the relationship between energy companies and their customers. In the USA, with its more interventionist regulatory framework, some state governments have attempted to use lost-revenue adjustment mechanisms and performance-based incentives to decouple utility revenues from sales, thus changing companies' business models (Brown and Wang 2017). However, this is not an option in EU countries. Rather, the introduction of EEOS was expected to encourage and incentivise energy retailers to become more like energy service companies, ESCOs-which exist throughout Europe (Bertoldi and Boza-Kiss 2017). The evidence for these changes is mixed (ENSPOL 2015a). Energy distributors in Denmark are reported to have used EEOS to develop better customer relationships. In Italy, the EEOS has supported a growing market for ESCOs, although not the transformation of energy companies into ESCOs. In France, the source of EEOS programmes/funding is not understood by recipients, and in the UK, the energy retailers have not notably changed their business model. While EEOS can be an important efficiency driver, this policy is not sufficient to fundamentally move energy retailers away from being kilowatt hour selling businesses.

\section{EEOS in different framings of energy efficiency}

The flexibility of EEOS also leads to their meaning and aims changing over time, in a similar way that interpretations of energy efficiency can change (Mallaburn and Eyre 2013). For example, they can be designed to deliver reductions in fuel poverty, to generate job opportunities in chosen sectors (see for example the DECC (2014b) estimate of 28,000-34,000 jobs supported by EEOs in the UK), or to grow the market for particular technologies, as well as to deliver savings. As the policy objectives change, so the design of the policy is likely to change. This flexibility probably means that EEOS can be relevant; however, energy efficiency is framedwhether as an aid to economic efficiency, as first fuel 
or as a means to delivering multiple social, economic and environmental benefits. However, it is worth considering how EEOS fits with two currently popular framings - 'energy efficiency first' or 'first fuel' and with energy efficiency as a means to achieve multiple benefits (IEA 2014).

The policy approach proposed in the Winter Package is 'energy efficiency first'. Arguably, this framing implies a role for EEOS within the way the energy sector is regulated and structured - although how that plays out will depend on the national regulatory structures and the industry. EEOS naturally are a good fit with the new policy principle - although they were first implemented in vertically integrated markets (in the USA), where requiring energy companies to provide energy efficiency in addition to energy is perhaps easier (Rosenow et al. 2016a).

A multiple benefits framing suggests that energy efficiency has many environmental, social and economic benefits, such as improved health, new job creation and increased productivity, and that these are not properly understood or taken account of in decision-making (IEA 2014). Some of these benefits are quantifiable, with good-quality data and agreed methodologies, and can already be included in policy design and evaluation, or individual and organisational decision-making (BEIS 2018; Rasmussen 2017). Article 7 has only been structured to deliver energy savings; it does not consider the multiple benefits of energy efficiency. While the proposals for a revised Article 7 do include considerations of the social benefit of ensuring that households in energy or fuel poverty benefit from the scheme, this is about distribution of benefits not broadening the definition of benefits. Including multiple benefits in policy design could affect targets set for EEOS, e.g. higher targets can be set if energy efficiency is shown to deliver societal benefits beyond energy saving. Given that it is government which has multiple social, environmental and economic objectives which can be delivered via energy efficiency - rather than the obligated partiesthe interaction of multiple benefits framing with this policy needs some careful thought.

What would it take for EEOS not to have a future?

One of way of thinking about the future place of EEOS in EU policy is to consider what would make this policy redundant. Assuming that there is a strong energy savings target still in place, the following conditions might mean EEOS are no longer needed:

1. No significant energy efficiency potential available from standardised measures, or little available in the sectors which typically deliver most savings via EEOS

2. EEOS policy is shown to fail in terms of efficacy/ efficiency/cost-efficiency/equity

3. Energy company resistance to delivering this aspect of government energy policy

4. Public/political resistance to energy price rises

5. A stronger focus on distributional issues of policy, so that regressive revenue raising via (residential) energy customers, or highly unequally distributed benefits were not acceptable

6. Energy companies become more like ESCOs-so that they already deliver an (economically) optimum amount of energy efficiency — or this function is delivered by other market actors.

Condition 1 does not apply generally, with plenty of energy efficiency potential identified within, for example the buildings sector (Graham et al. 2013) and SMEs (IEA 2015). However, the requirements of the Ecodesign Directive have ensured domestic appliances and lighting are no longer included in EEOS programmes. These standardised measures, which formerly delivered savings through this policy route, have become mandatory. Even in the long term, an argument can be made that innovation will lead to regrowth of 'low-hanging fruits' (Gilleo 2014). Condition 2 would be unlikely based on evidence to date- but poorly designed and implemented schemes could fail to achieve the successes of the past, as discussed earlier. As we have shown, Condition 3 was a factor in the UK scheme being designed to be less ambitious, as was Condition 4 . While in some countries it seems that EEOS have been influential in redesigning energy companies' relationships with their customers (e.g. Denmark), this is not universally true and continued support of energy companies for this policy cannot be taken for granted. The Commission is trying to address Condition 5 by its inclusion of a requirement to deliver some of the benefits of EEOS to those in energy/fuel poverty. However, there is also the issue of unequal distribution of benefits, which applies particularly in the residential sector for more expensive measures, and could also be an issue in the industrial/commercial sector. Concerns about the 
regressive nature of this policy remain (Barrett et al. 2018). The evidence shows we are a long way off energy companies becoming ESCOs. However, Condition 6 may be met if the new business models developed by aggregators, ESCOs or commercial and development banks deliver significant energy efficiency savings from large number of customers, reducing or removing the role of energy companies in delivering energy efficiency.

Securing a strong and effective future for EEOS

On balance, there is still good policy space for EEOS for those member states which choose to use them. However, there are also risks, most notably a lack of energy company, public or political support for this policy. Energy companies can have internal reasons for opposing the policy (too burdensome, not their core business etc.), which they may present as protecting their customers from rising prices due to unnecessary government policy. In order to maintain public and political support, it is vital that the policy has support from trusted actors and interest groups (e.g. consumer groups, environmental and social NGOs), and that the evidence is available to show its benefits. This evidence must be communicated clearly and persuasively. EEOS cannot remain a policy only understood by a few experts.

An important conclusion from the experience over the past decade is that a rigorous and public process of review can drive innovation in delivery routes, can build greater public awareness of the services being offered and is quite useful, perhaps essential, to ever-deeper savings levels over a period of years. EEOS are unlikely to meet deeper savings targets over multi-year periods without the discipline of programme reviews, including ex-post evaluation and policy redesign, leading to innovations in implementation.

Finally, experience shows that relying on EEOS as the only instrument to deliver energy efficiency measures is risky. When political support for levy-funded energy efficiency policy drops, this could have significant repercussions for the sustainability of the energy efficiency market. Using EEOS as a single instrument also does not exploit the potential synergies with other, complementary measures and a policy mix has been shown to be more effective than relying on single instruments (Rosenow et al. 2016b). The significant carbon reduction required following the Paris Agreement is likely to require the full suite of policy instruments in order to achieve energy efficiency improvements at scale. This includes innovative instruments such as energy efficiency feed-in tariffs (Bertoldi et al. 2013; Eyre 2013), linking carbon offset mechanisms with tradable 'white certificates' from EEOS (Oikonomou et al. 2012) and auctions (IEA 2017).

\section{Conclusions}

An energy efficiency obligation scheme, correctly designed, can successfully deliver sustained energy savings over multiple years. It is flexible and can be designed in a variety of way to meet national needs, and to fit within very different policy mixes. EEOS have been used to deliver savings primarily through upgrading the building stock, early replacement of inefficient appliances and equipment, and improving industrial processes - efficiency savings which are not covered by minimum standards or regulations. EEOS have delivered considerable energy savings and are expected to do so into the future. In total, $15 \mathrm{EU}$ countries now have an EEOS, while the other member states have not adopted EEOS and are not currently planning to do so. In addition, as EEOS have delivered higher energy savings in Denmark and the UK, there has been public and political concern about the cost to bill payers, and this influenced the reduced ambition levels of the UK and Danish EEOS.

EEOS are likely to continue to evolve in objectives, design and delivery as the energy and policy landscape changes around them. The new European framework of 'energy efficiency first' supports EEOS, and the planned extension of the Energy Efficiency Directive to 2030 is also vital. EEOS have a very strong track record in securing savings from low-cost measures and they are expected to continue to do so. However, their scope may need to widen as savings targets increase, and if (or when) low-cost opportunities reduce over time. Delivering higher cost measures, particularly deep retrofit to buildings, is very challenging whatever policy instrument or policy mix is used. EEOS may be able to make a contribution to this, but careful thought will be needed to ensure that the policy is seen as fair, and retains energy company, public and political support. The expertise and evidence which exists showing the benefits of EEOS needs to be shared with and understood by wider civil society, so that this is not a policy only understood by experts. 
Funding information Tina Fawcett's contribution was funded by the UK Research Councils (grant no: EPSRC EP/L024756/1) as part of the Decision Making Theme of the UK Energy Research Centre Phase 3. Part of Jan Rosenow's time was funded by the UK EPSRC through the Centre for Innovation and Energy Demand (CIED; http://cied.ac.uk/; grant no: EP/KO11790/1).

\section{Compliance with ethical standards}

Conflict of interest The authors declare that they have no conflict of interest.

Open Access This article is distributed under the terms of the Creative Commons Attribution 4.0 International License (http:// creativecommons.org/licenses/by/4.0/), which permits unrestricted use, distribution, and reproduction in any medium, provided you give appropriate credit to the original author(s) and the source, provide a link to the Creative Commons license, and indicate if changes were made.

\section{References}

ATEE. (2017). Snapshot of energy efficiency obligation schemes in Europe: 2017 update. Association Technique Energie Environnement. [Online] Available: http://atee. fr/sites/default/files/part_6-_2017_snapshot_of_eeos_in_ europe.pdf [Accessed February 2018].

Bach, P. (2016). The Danish Energy Efficiency Obligation System. Joint Research Centre, European Commission, Presented at workshop on energy savings under EED Article 7, Brussels, 16 November 2016. [Online] Available: http://e3p-beta.jrc. $\mathrm{nl} /$ sites/default/files/files/documents/Presentations/07_mr. bach_eeos_in_denmark.pdf [Accessed January 2017].

Barrett, J., Owen, A., Taylor, P. (2018). Funding a low carbon energy system: a fairer approach? UKERC policy briefing. [Online] Available http://www.ukerc.ac.uk/publications/funding-a-lowcarbon-energy-system.html [Accessed March 2018].

BEIS. (2017a). Energy company obligation: help to heat, April 2017 to September 2018: The Government response to the ECO Help to Heat consultation. Department for Business, Energy and Industrial Strategy. [Online] Available: https://www.gov. uk/government/consultations/energy-company-obligation-ecohelp-to-heat [Accessed October 2017].

BEIS. (2017b). The clean growth strategy: leading the way to a low carbon future. London: Department for Business, Energy and Industrial Strategy.

BEIS. (2018). Valuation of energy use and greenhouse gas: supplementary guidance to the HM Treasury Green Book on appraisal and evaluation in central government. Department for Business, Energy and Industrial Strategy. [Online] Available: https://www. gov.uk/government/publications/valuation-of-energy-use-andgreenhouse-gas-emissions-for-appraisal [Accessed February 2018].

Bertoldi, P., \& Boza-Kiss, B. (2017). Analysis of barriers and drivers for the development of the ESCO markets in Europe. Energy Policy, 107, 345-355.
Bertoldi, P., Rezessy, S., Lees, E., Baudry, P., Jeandel, A., \& Labanca, N. (2010). Energy supplier obligations and white certificate schemes: comparative analysis of experiences in the European Union. Energy Policy, 38, 1455-1469.

Bertoldi, P., Rezessy, S., \& Oikonomou, V. (2013). Rewarding energy savings rather than energy efficiency: exploring the concept of a feed-in tariff for energy savings. Energy Policy, 56, 526-535.

Bertoldi, P., Castellazzi, L., Oikonomou, V., Fawcett, T., Spyridaki, N.A., Renders, N., Moorkens, I. (2015). How is article 7 of the Energy Efficiency Directive being implemented? An analysis of national energy efficiency obligation schemes. Proceedings of ECEEE Summer Study. European Council for an Energy-Efficient Economy, Presqu' Ile de Giens, France.

Brown, M. A., \& Wang, Y. (2017). Energy-efficiency skeptics and advocates: the debate heats up as the stakes rise. Energy Efficiency, 10(5), 1155-1173.

Bundgaard, S.S., Dyhr-Mikkelsen, K., Hansen Kjaerbye, V., Togeby, M., Sommer, T., Larsen, A.E. (2013). Spending to save: evaluation of the energy efficiency obligation of Denmark, Proceedings of ECEEE Summer Study. European Council for an Energy Efficient Economy, Presqu' Ile de Giens, France.

CCC. (2015). The fifth carbon budget: the next step towards a lowcarbon economy. London: Committee on Climate Change.

DECC. (2011). Extra help where it is needed: a new energy company obligation. London: Department of Energy and Climate Change.

DECC. (2013). Energy efficiency strategy: 2013 update. London: Department of Energy and Climate Change.

DECC. (2014a). The future of the energy company obligation: government response to the 5 March 2014 consultation. London: Department of Energy and Climate Change.

DECC. (2014b). The future of the energy company obligation: final impact assesment. London: Department of Energy and Climate Change.

DECC. (2016). ECO: help to heat: consultation document. London: Department of Energy and Climate Change.

ENSPOL. (2015a). Energy saving policies and energy efficiency obligation scheme: D2.1.1 Report on existing and planned EEOs in the EU, Part 1: evaluation of existing schemes. [Online] Available at: http://enspol.eu/results [Accessed June 2015].

ENSPOL. (2015b). Energy saving policies and energy efficiency obligation schemes: D2.2 Energy Efficiency Obligations outside the EU, [Online] Available at: http://enspol.eu [Accesssed January 2016].

ENSPOL. (2015c). Report on alternative schemes to energy efficiency obligations under Article 7 implementation, [Online] Available at: http://enspol.eu.results [Accessed October 2015].

European Commission. (2014). Benchmarking smart metering deployment in the EU-27 with a focus on electricity. [Online] Available at: http://ses.jrc.ec.europa.eu/smartmetering-deployment-european-union [Accessed November 2017].

European Commission. (2016a). Clean energy for all Europeans-unlocking Europe's growth potential. Brussels: European Commission. 
European Commission. (2016b). Proposal for a Directive of the European Parliament and for the Council amending Directive 2012/27/EU on energy efficiency. Brussels: European Commission.

European Parliament. (2016). MEPs call for more ambitious and consumer-focused energy targets beyond 2020, [Online] Available: http://www.europarl.europa.eu/news/en/newsroom/20160622IPR33205/meps-call-for-more-ambitiousand-consumer-focused-energy-targets-beyond-2020 [Accessed January 2017].

European Parliament. (2018). MEPs set ambitious targets for cleaner, more efficient energy use, [Online] Available: http://www.europarl.europa.eu/news/en/press room/20180112IPR91629/meps-set-ambitious-targets-forcleaner-more-efficient-energy-use [Accessed February 2018].

Eyre, N. (2013). Energy saving in energy market reform - the feed in tariffs option. Energy Policy, 52, 190-198.

Eyre, N., Bodineau, L., Pavan, M. (2009). Energy company obligations to save energy in Italy, the UK and France: what have we learnt?, Proceedings of ECEEE Summer Study. European Council for an Energy Efficient Economy, Presqu' Ile de Giens, France.

Fawcett, T., Rosenow, J. (2016). The Member States' plans and achievements towards the implementation of Article 7 of the Energy Efficiency Directive. In A. Zgierewicz (Ed.), Implementation of the energy efficiency directive: energy efficiency obligation schemes. European Parliament, [Online] Available: http://www.europarl.europa. eu/RegData/etudes/STUD/2016/579327/EPRS STU\%282016\%29579327_EN.pdf. [Accessed December 2016].

Forster, D., Kaar, A.-L., Rosenow, J., Leguijt, C., Pato, Z. (2016). Study evaluating progress in the implementation of Article 7 of the Energy Efficiency Directive Final Report: report for DG energy. Ricardo Energy \& Environment, [Online] Available: https:/ec.europa.eu/energy/sites/ener/files/documents/final report_evaluation_on_implementation_art._7_eed.p $\overline{\mathrm{df}}$ [Accessed December 2016].

Gilleo, A. (2014). Picking all the fruit: all cost-effective energy efficiency mandates, Proceedings of the 2014 American Council for an Energy-Efficient America (ACEEE) Summer Study on Energy Efficiency in Buildings: The Next Generation - Reaching for High Energy Savings ACEEE, Pacific Grove, Washington, pp. 8-75-78-87.

Graham, P., Laustsen, J., Ürge-Vorsatz, D. (2013). Going deep in energy consumption in buildings: how to achieve the best case scenario for deep savings in building energy consumption, Proceedings of ECEEE Summer Study. European Council for an Energy-Efficient Economy, Presqu' Ile de Giens, France.

Grunewald, P. (2016). Flexibility in supply and demand. DEMAND Centre Conference, Lancaster, 13-15 April 2016. [Online] Available: www.demand.ac.uk/wpcontent/uploads/2016/03/DEMAND2016_Full_paper_3Grunewald.pdf [Accessed December 2016].

IEA. (2014). Capturing the multiple benefits of energy efficiency. Paris: International Energy Agency.

IEA. (2015). Accelerating energy efficiency in small and mediumsized enterprises: powering SMEs to accelerate economic growth. Paris: International Energy Agency.
IEA. (2016). Energy efficiency market report 2016. Paris: International Energy Agency.

IEA. (2017). Market-based instruments for energy efficiency. Paris: International Energy Agency.

Labanca, N., \& Bertoldi, P. (2016). Energy saving calculation methods under Article 7 of the Energy Efficiency Directive: report for DG energy. Ispra, Italy: Joint Research Centre.

Lees, E., Bayer, E. (2016). Toolkit for energy efficiency obligations. Regulatory Assistance Project, [Online] Available: www.raponline.org/document/download/id/8029 [accessed January 2017].

Mallaburn, P., \& Eyre, N. (2013). Lessons from energy efficiency policy and programmes in the UK from 1973 to 2013. Energy Efficiency, 7, 23-41.

Mundaca, L., \& Neij, L. (2009). A multi-criteria evaluation framework for tradable white certificate schemes. Energy Policy, 37(11), 4557-4573.

Nadel, S., Cowart, R., Crossely, D., Rosenow, J. (2017). Energy saving obligations across three continents: contrasting approaches and results Proceedings of ECEEE Summer Study. European Council for an Energy-Efficient Economy, Presqu' Ile de Giens, France.

Oikonomou, V., Flamos, A., Spyridaki, N-A., van der Gaast, W., De Dominicis, A., Chung, N. (2012). White certificates and domestic offset schemes: possible synergies. Mitigation and Adaptation Strategies for Global Change 17(2), 187-205.

Parag, Y., \& Sovacool, B. K. (2016). Electricity market design for the prosumer era. Nature Energy, 1, 16032.

Pereira, G. I., \& Pereira da Silva, P. (2017). Energy efficiency governance in the EU-28: analysis of institutional, human, financial and political dimensions. Energy Efficiency, 10, 1279-1297.

RAP. (2012). Best practices in designing and implementing energy efficiency obligation schemes: Research Report Task XXII of the International Energy Agency Demand Side Management Programme. IEA DSM \& RAP (Regulatory Assistance Project), [Online] Available: http://www.ieadsm.org/ [Accessed October 2014].

Rasmussen, J. (2017). The additional benefits of energy efficiency investments - a systematic literature review and a framework for categorisation. Energy Efficiency, 10, 1401-1418.

Republic of Bulgaria. (2016). Annual report on the implementation of the National Energy Efficiency Action Plan. European Commission, [Online] Available: https://ec. europa.eu/energy/sites/ener/files/documents/BG\%202016 $\% 20 \% 20$ Energy $\% 20$ Efficiency\%20Annual\%20Report_en. pdf [Accessed January 2017].

Ricardo-AEA. (2015). Study evaluating the national policy measures and methodologies to implement Article 7 of the Energy Efficiency Directive. Study produced for DG ENER, [Online] Available: https://ec.europa. eu/energy/sites/ener/files/documents/Final\%20Report\%20 on\%20Article\%207\%20EED.pdf [Accessed February 2016].

Rohde, C., Rosenow, J., \& Eyre, N. (2015). Energy saving obligations. Cutting the Gordian knot of leverage? Energy Efficiency, 8, 114-129.

Rosenow, J. (2012). Energy savings obligations in the UK-a history of change. Energy Policy, 49, 373-382.

Rosenow, J. (2013). Politics of change - energy efficiency policy in Germany and the UK. DPhil thesis. University of Oxford, UK. 
Rosenow, J., Bayer, E. (2016). Costs and benefits of Energy Efficiency Obligation Schemes. Report for the European Commission. RAP, [Online] Available: https://ec.europa. eu/energy/sites/ener/files/documents/final_report_on_study_ on_costs_and_benefits_of_eeos_0.pdf [Accessed December 2016].

Rosenow, J., \& Eyre, N. (2016). A post mortem of the Green Deal: austerity, energy efficiency, and failure in British energy policy. Energy Research \& Social Science, 21, 141-144.

Rosenow, J., Bayer, E., Genard, Q., Toporek, M., Rososińska, B. (2016a). Efficiency first: from principle to practice. Real world examples from across Europe. Energy Union
Choices, [Online] Available from: http://www.raponline. org/wp-content/uploads/2016/11/efficiency-first-principlepractice-2016-november.pdf [Accessed December 2016].

Rosenow, J., Fawcett, T., Eyre, N., \& Oikonomou, V. (2016b). Energy efficiency and the policy mix. Building Research \& Information, 44, 562-574.

UNFCCC. (2015). Decision 1/CP.21: adoption of the Paris Agreement. United Nations Framework Convention on Climate Change. [Online] Available: http://unfccc. int/resource/docs/2015/cop21/eng/10a01.pdf [accessed March 2016]. 